\title{
A Study on the Relationship between Festival and Special Event Attitude, City Brand Image and Behavioral Intentions from the Perspective of Visitors
}

\author{
Hui Li ${ }^{\mathrm{a}}$, Mengfei Jin ${ }^{\mathrm{b}}$ \\ International College of Business and Technology, Tianjin University of Technology, Tianijn \\ 300384, China. \\ alhsnow@163.com, bjmf940310@163.com
}

Keywords: Visitors, Festival and Special Event (FSE), Visitor’s Attitude, City Brand Image, Visitor’s Behavioral Intention

Abstract: In recent years, more and more cities in China held festival and special events (FSE) to improve their competitiveness and build their brands. Based on the literature review, this paper takes the visitors as the research perspective, analyzes the relationship between the visitors' attitude to the FSE, the city brand image and the behavioral intentions of city visitors, and constructs a conceptual framework. In this paper, visitor's attitude is divided into three parts according to the stage of FSE: pre-event (FSE image evaluation, FSE participation motivation), during the event (FSE experience, FSE emotions), and post-event (FSE evaluation, FSE satisfaction, FSE loyalty). City brand image includes two dimensions, brand cognitive image and brand affective image. The visitor's behavioral intention is mainly his or her re-visit intention.

\section{Introduction}

With the rapid development of urbanization and tourism in China, As a tourist stimulus, FSE marketing has attract the attentions of city managers. Especially, some cities lacking natural tourism resources can attract more tourists to visit the city by hosting some FSEs, and then enhance the competitive competence of the hosting city. For those cities with rich natural tourism resources, they also can promote the development of tourism by holding FSE on the basis of their natural resources, not only stimulating the tourism development, but also increasing the city image and building the city brand.

The related research of FSE marketing has attracted considerable attention of theoretical and practical fields. The existing FSE marketing research mainly focuses on competitiveness, attractiveness, loyalty of visitors to FSE and destinations, satisfactions and evaluation of tourists on the FSEs, and destination image. In most research papers, the scholars have verified that tourists are the core factors of effective service marketing, and the tourists' motivations, attitudes, experiences, perceptions and other key elements will directly affect the effectiveness of the FSEs. Therefore, depth understanding of the visitors is very necessary for the city managers to design proper FSE marketing strategy. However, the current research on the relationship among the influential factors 
of FSE marketing on visitors' perspective is independent and dispersed, and there is not a clear theoretical framework. This study considers the different stage of FSEs into the framework, including pre-event, during the event, and post-event. On the perspective of visitors, this study tries to integrate the characteristics of different FSE stages, and establishes a conceptual framework of the relationship between FSE attitudes, the city brand image and the behavioral intentions based on the perspective of visitors, to understand better the links between tourists' psychological thoughts and views on the FSE, and propose some useful policy recommendations for planning FSE marketing activities successfully, developing the hosting city's tourists industry, and promoting the city’s brand image and competitiveness.

\section{Related Concepts of FSEs}

Since the 1960s, event tourism marketing has been studied by scholars, but Getz (1991) first proposed "Festival and special event”(FSE) this term. He regards FSE as "an opportunity for leisure, social or cultural experience outside the normal range of choices or beyond everyday experience". After that, lots of scholars began to study FSE marketing from different perspectives. Crowther and Donlanis (2011) emphasis that a well implemented event marketing strategy is very important to create value spaces for the hosting city. Lee and Hsu (2013) discuss the relationship between visitor's motivations and satisfactions during the events, and the results shows there is a positive relationship between these two factors. Chinese scholars began to study FSE marketing in recent 20 years. Dai (2003) considers that the "public theme festivals" usually includes traditional festival celebrations and various festivals made by special purpose planning. Dai and Gai (2011) promote that there is a positive relationship between attitudes, city image, and tourists' experiences. Zhu and Jiang (2012) use ANOVA analysis to analyze the visitor's motivations to participate FSEs. Li and Gu (2016) pay more attention on the visitors' consuming intentions, and give some suggestions on how to improve products and brands.

\section{Relationship Analysis}

\subsection{General Conceptual Framework}

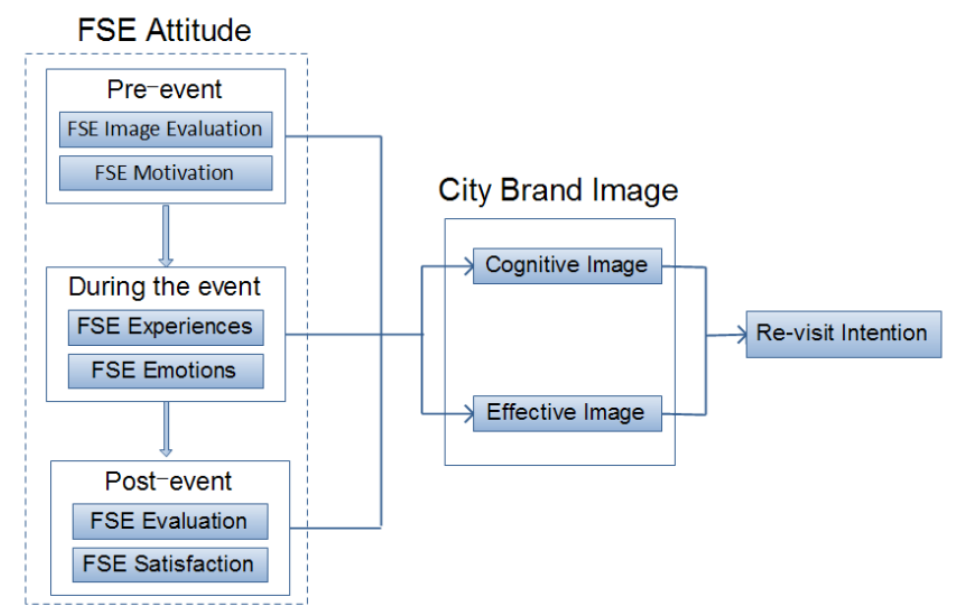

Fig. 1 Conceptual Framework

According to the extant literature, the attitudes of hosting city tourists on FSE are divided into three stages: pre-event, during the event, and post-event. Pre-event attitudes refer to the visitors' views on the FSE before their participation, including the FSE image evaluation and the motivation to participate the FSE. During the event attitudes refer to the perception of the visitor in the process 
of participating in the FSE, including visitor's experiences and visitor's emotions. The post-event attitudes refer to the feeling of the visitors after they participated in the FSE, including FSE evaluations and visitor's satisfactions. The city brand image includes brand cognitive image and affective image. The FSE is held in order to shape the hotting city image and finally attract more visitors to re-visit the city again. Based on literature review and analysis, the conceptual framework is proposed (see Fig. 1) to show the relationship between visitors' FSE attitudes, the city brand image evaluations, and their behavioral intentions.

\subsection{Relationship among FSE Attitudes in Different Stages}

First, the visitors' FSE image evaluations and participation motivation of the FSE determine whether the visitors participate in the FSE. Better FSE image evaluations and strong participate motivation will increase the possibility of visitors participating in the FSE, and also promote the emotions subconsciously (Cheon, 2016). They might have strong willingness to experience the activities in the FSE, and promote positive emotions. Second, the experiences and emotions in the process of FSE is the most directly feeling to the visitors. A better experience and positive emotion can result in a good evaluation of the FSE, and then enhance the visitors' satisfactions (Westwood, 2018).

\subsection{Relationship between FSE Attitudes and City Brand Image}

City brand image becomes more and more important in the city marketing strategy, and has been a valuable tool for tourists to select destination. City managers always like to combine city brand and FSE brand together to improve the city's competitiveness. City brand image includes cognitive image and affective image. With the improvement of visitors' attitudes on the FSE, their evaluations on FSE might be transferred to hosting city image evaluations according to Brand Image Transfer theories. The positive attitudes on FSE might increase their evaluations on the host city brand image (Ramseook-Munhurrun, et al. 2009).

\subsection{Relationship between City Brand Image and Visitor’s Behavioral Intention}

According to the attitude-behavior relationships theory, the positive attitudes will increase the customers' positive subsequent behavior (Ahmed, 1996). This theory is also applicable in FSE marketing activities. The ultimate purpose of building the city's brand image is to attract more visitors to have the willingness to visit the city again, and accordingly improve the tourist development of the city and enhance the competitiveness. When the evaluation of the city's brand image is improved, the positive image of the city will be transferred to their deep memories. In previous studies, scholars have shown that the overall image of destination not only plays a role in the selection of tourists choosing a destination, but also affects the behavior of tourists in the future. Stylos et al. (2017) studies and confirms that there is a significant positive impact between city image evaluations and the visitors' potential behavior intentions.

\section{Conclusion}

(1) This study integrates the influential factors of FSE marketing strategy on the perspective of visitors, and proposes a general conceptual model about the relationship between visitors' attitudes, city brand image evaluations, and their behavioral intentions in future. The visitors' attitudes on FSE activities has a significant positive influence on the city brand image evaluations, and the city brand image evaluations also has a significant positive influence on the visitors' behavioral 
intentions. A successful FSE marketing activity should pay more attention to the visitor's attitudes on FSE, and encourage more tourists to re-visit the city.

(2) This study considers the stage of FSE into the framework, and divides the FSE marketing into 3 stages: pre-event, during the event, and post-event. To test the pre-event FSE attitude, this paper suggests two factors: FSE image evaluation and FSE motivation. To test the FSE attitude during the event, two factors are suggested: FSE experiences and FSE emotions. To test the post-event FSE attitude, two factors are suggested: FSE evaluations and FSE satisfactions. All of these factors will influence the city brand image evaluations. Furthermore, there is relationship among these factors in the three stages. This concept shows that FSE marketing strategy is a process. The city manager should not only consider the implement of FSE when it held, but also pay more attention to the pre and post event stage. The visitors' attitudes in the three stage of FSE activities are all important influential factors of successful FSE marketing strategies.

This paper focuses on the visitor's perspective, and propose a model to test the visitor's re-visit intention. It is a long-term tourism effect of FSE marketing. The short-term tourism effect is the most intensively studied field in FSE marketing research. However, the FSE marketing can bring further influence on city tourism. The host city can improve the destination brand image by improving visitors' FSE attitudes, including providing better infrastructure of the city, increasing accessibility of the city, developing good activities, and increasing the media exposure of the city, and then attract more tourists to re-visit in future.

\section{Acknowledgment}

This work was supported by the National Social Science Foundation of China Project: Study on the Influence of Event Marketing on the Host City Brand in the Perspective of City Customers, Grant No. 15BGL085

\section{References}

[1] Getz D. 1991. Assessing the economic impacts of festivals and events, Journal of Applied Recreation Research, Vol. 1(11-19).

[2] Crowther, P., Donlanis, L. 2011. Value-creation space: the role of events in a service-dominant marketing paradigm, Journal of Marketing Management, Vol. 27(1444-1463).

[3] Lee, T. H. Hsu F.Y.2013.Examining how attending motivation and satisfaction affects the loyalty for attendees at aboriginal festivals. International Journal of Tourism Research, Vol. 15(18-34).

[4] Dai G.Q., Bao J.G. 2003. The concept, content, method and inspiration of the study of events and event tourism in the west (first volume). Tourism Tribune, Vol. 5 (26-24).

[5] Zhu S.H., Jiang H.T. 2012. Motivation research on festivals and special events: the case study of the international plum blossom festival of Nanjing, China, Joural of Beijing Internation Studies University, Vol. 11(66-72).

[6] Li H., Gu Y.Y. 2016. The Influence of Festival and Special Event Marketing on the Visitors' Intentions to Visit theHosting Cities. Special Zone Economy, Vol. 9 (121-122).

[7] Cheon, Y.-S. 2016. A study on the relationship among physical environment of festivals, perceived value, participation satisfaction, and festival image. International Review of Management and Marketing, Vol. 6 (23-36).

[8] Westwood, C., et al. 2018 Agricultural shows: visitor motivation, experience and behavioural intention. International Journal of Event and Festival Management. Vol. 9 (147-165).

[9] Ramseook-Munhurrun, P., et al. 2009. Examining the Structural Relationships of destination image, perceived value, Tourist Satisfaction and Loyalty: Case of Mauritius. Procedia - Social and Behavioral Sciences. Vol. 175 (252-259).

[10] Ahmed, Z. U. 1996. The need for the identification of the constituents of a destination's tourist image: a promotional segmentation perspective. Tourism Review, Vol. 51(44-57).

[11] Stylos, N., et al. 2017. Linking the dots among destination images, place attachment, and revisit intentions: A study among British and Russian tourists. Tourism Management, Vol. 60 (15-29). 